\title{
ROLE OF WOMEN IN SECURITY AND DEFENSE: BULGARIAN NATIONAL POLICIES AND EXPERIENCE
}

\author{
Nevena ATANASOVA - KRASTEVA \\ "Vasil Lesvski" National Military University, Veliko Tarnovo, Bulgaria \\ nevena_atanasova@abv.bg
}

\begin{abstract}
The paper focuses on the policies for gender equality which can and should be understood as a long-term investment, not as a situational solution or a short-term cost, especially in military environment. On the basis of the UN Security Council Resolution 1325 - "Women, peace and security", the National plan for implementation of the Resolution 1325 in the MoD in Bulgaria has been analyzed. New policies or initiatives concerning the implementation of gender in the Bulgarian Armed Forces are included with the actual information about female active duty military personnel and the perspectives to overcome the prejudices and stereotypes in people's minds.
\end{abstract}

\section{Keywords: gender, implementation of good policy, UNSC Resolution 1325}

"The world of humanity has two wings - one is women and the other men.

Should one wing remain weak, flight is impossible"

\section{Introduction.}

One of the most widely discussed and promising topics, quite relevant since the beginning of the 21 st century, is related to gender issues. Terms such as gender equality, equality between men and women, gender mainstreaming are very common in public and scientific space. According to many authors, the equality between women and men is not a factor whose influence will be applied to half of the mankind. Its impact will affect all sides of the society. Nowadays many organizations and people work hard to support different activities and efforts to protect human rights and at the same time to promote the real place of women and girls in all aspects of life. Improving the status and well-being of women is a popular tendency because of the world processes connected with the perspective to create more coherent gender equality mechanisms. In that case all people must be participants in the formation of the DOI: 10.1515/kbo-2017-0001

(C) 2017. This work is licensed under the Creative Commons Attribution-NonCommercial-NoDerivatives 3.0 License.
Baha'i writings

just society and therefore the opinion of the same civil society is important for the discussions in the biggest and most influential words communities and organizations.

That's why the understanding of the equality between men and women has a long history during its implementation and implications for the society. "...the equality of women and men is a facet of human reality and not just a condition to be achieved for the common well-being. What makes human beings human - their inherent dignity and nobility - is neither male nor female. The search for meaning, for purpose, for community; the capacity to love, to create... has no gender. This has profound implications for the organization of every aspect of human society." [7]. We can add that the gender issue is not only connected with social justice and diversity in the surrounding social environment. 
The equality appears to be a condition for achieving the goals of each organization, the existence of competitiveness and creating opportunities for social cohesion.

\section{Body.}

Different practices have shown that investing in policies for gender equality has turned out to be a sustainable and timely solution to old and new problems and challenges in the last 15 years. Therefore when we're analyzing the content of a number of international documents - for example - UN resolutions and national strategies and plans for their implementation, we can make the conclusion that the policies for gender equality can and should be understood as a long term investment, not as a situational solution or a short-term cost.

Many of the contemporary publications are devoted to the real place and problems of women at the different levels of political, economic and social life. An important part of scientific and popular research is aimed to the female participation in the decision making process. According to V. Norville "Building lasting peace and security requires women's participation. Half of the world's population cannot make a whole peace." [3]

With relation to this, we should point out that the adoption of United Nations Security Council Resolution 1325 in 2000 is seen as a historic recognition by the international community of the negative effect that armed conflicts have on women and children in particular, as civilians, refugees or internationally displaced persons. The UNSC Resolution 1325 "Woman, peace and security" totally changed the focus of the important roles which women play as leaders and participants in security efforts - for example, prevention of or helping in conflicts, peace building, developing postconflict reintegration efforts, and improving the standard of life. Women insist that their knowledge and skills, their leadership abilities, their full potential be tapped in the governance. "Today, this is increasingly framed as not only the "right" thing to do, but also the "smart" thing to do." [2]

In the context of the Armed Forces, where the working environment is gender mixed, it is particularly important that both women and men feel engaged in gender issues. Additionally the two sexes have to be convinced of the benefits of efficient gender equality policies for the society as a whole.

To achieve progress in this direction, an essential role in the changing of the still existing negative stereotypes and attitudes is attributed to the education of people, media messages and the government's practices. Unfortunately, gender stereotypes in society continue to persist and to be transmitted through modern education and developed culture. In most countries, women and men often follow the traditional models of education that actually lead to career opportunities for women in professional fields with lower wages. That is why, one of tasks is to advise and encourage young men and women to choose non-traditional routes / areas in their educational development.

But to be honest, more than 10 years after the United Nations Security Council passed Resolution 1325 with the recommendation to increase women's participation in issues of global security, the numbers of women with real participation in peace solutions remain marginal. And in spite of all improvements which have been made, women still remain underrepresented in public office, at the negotiating table or in peacekeeping missions. It should not be forgotten that the continuing lack of physical security and the existence of serious legal constraints in postconflict societies hamper women's integration into economic life and leadership. [3]

The service in the Armed Forces of the Republic of Bulgaria is a good example of the entry of female soldiers in the so-far purely "male territory" of the Bulgarian Army. 
The national plan for implementation of UN Security Council Resolution 1325 in the Ministry of Defence of Bulgaria exists from 2011. At a national level the body responsible for consultations, cooperation and coordination among the governmental and Non-governmental organizations in the elaboration and realization of the national policy on gender equality is the National Council on gender equality under the Council of Ministers.

The Deputy Defence Minister is a member of the National Council on gender equality. The Council of Ministers has adopted an Annual national action plan for promotion of gender equality. This plan follows the goals, set out in the National strategy for promotion of gender equality for the period $2009-2015$.

The plan for the implementation of Resolution 1325 of the UN Security Council in the Ministry of Defense is a serious and responsible sign to the Bulgarian and international community of the priorities and main steps of the management of the Ministry of Defense and Armed Forces with the idea to implement the Euro-Atlantic policies in this area.

The goals in the Action plan for implementation of United Nations Security Council Resolution 1325 at the Ministry of Defence are as follows: [1]

1. Provide mechanisms for the full implementation in the structures of the Ministry of Defense and Armed Forces of the principles set in Resolution 1325 of the UN Security Council.

2. Guarantee to the partners from the UN, EU, NATO and other international organizations with common values and principles that there is provided adequate contribution to allied operations.

3. An affirmation of Ministry of Defense of the Republic of Bulgaria as a leader in Southeast Europe in the implementation of policies on gender.

The plan for the implementation of Resolution 1325 in $\mathrm{MoD}$ of Bulgaria was developed jointly with the "BULGARIAN
ARMED FORCES WOMEN'S ASSOCIATION" - BUAFWA. This organization was established in 2006 as an NGO, and as a logical consequence of the increased proportion of women in the military units in the BG Army. The mission of BUAFWA is to promote and endorse the prestige and social status of women in the Armed Forces and to protect their common interests.

A good example of new policies or initiatives concerning the implementation of gender equality in the Bulgarian Armed Forces is connected with one of the guidelines in the National plan for implementation of UNSC Resolution 1325. This measure refers to the removal of the informal restrictions for women in professional fields, majors, specializations, degrees and forms of education in applying for acquisition of Bachelor Degrees in "Military field" with professional qualification - "Officer".

Thanks to the cooperation agreement signed between the MoD and the BUAFWA and after long creative discussions the above mentioned obstacle had been overcome. And this is already a fact - there isn't a quota for "men" and "women" applicants in the military academies. In the last 3-4 years the trainees and future officers have been classified on the basis of their results achieved on admission exams. And both sexes receive equal opportunity for development and further advancement. According to the statistical data, prepared for the NATO Committee on Gender Perspectives, in the last years more than 15 $\%$ of the total number of cadets at Bulgarian military educational institutions are females.

A proof for the right direction of the understanding of gender mainstreaming or gender perspective in $\mathrm{MoD}$ is the place Bulgaria takes with respect to the number of women in the armed forces as compared to other NATO member nation in 2015. The 2015 Summary of the National Reports of NATO member and partner nations to 
the NATO Committee on Gender Perspectives (NCGP) on the implementation of the United Nations Security Council Resolution 1325 on Women, Peace and Security represents active duty female military personnel in the Armed forces of NATO member nations in 2015, by country. This statistics Bulgaria is in the 7-th place with 15,2\% active duty female military personnel, after Hungary, Latvia, Slovenia, Greece, USA and France. [6]. Furthermore, comparing the number of men and women in the armed forces of NATO member nations in 2015, it is important to point out that Albania, Bulgaria, Canada, Czech Republic, France, Germany, Greece, Hungary, Latvia, Portugal, Slovenia, Spain, and USA are above the NATO average, which is $10.8 \%$ for women and $89.2 \%$ for men.

In the part "Retention Statistics in 2015" of the Report there is an analysis of the percentage of NATO member nations with retention policies that specifically target women." While $81 \%$ of NATO member nations have retention policies, $11 \%$ of them have particular retention policies for women." [6] There are provided the best examples among NATO member nations with regards to the adoption of specific retention policies for women in use in 2015. And in these examples we see Bulgaria with Spain and United Kingdom where specific retention policies for women are in place.

Another good gender policy in the Bulgarian Armed Forces can be defined as parental life and rights. Pursuant to the information in the National report of Bulgaria, the legal social support is given to mothers during pregnancy and both parents of a new-born child. According to the Labour Code, maternity leave is 410 days for each child and parental leave is 52 weeks for the mother as well as for the father and it is transferable between parents. Besides, there are specific programmes to support the work-life balance for military personnel such as the list of female military personnel which will have flexible working schedules. Another useful practice is the part-time employment and flexible hours which are allowed in case of parental leave and caring for elderly and sick people. There are special programmes to support parents when both serve in the armed forces or if parents are divorced or single. There is a child-care policy that includes provisions protecting parents from being deployed, breastfeeding breaks, policy on duty assignments, night duty, overtime work, flexible working and service hours or variable start/finish times during the working day.

All these good benefits as a result of the implementation of the different polices connected with gender equality in military environment provoke the new requirements for the leaders from all levels. It means that not only the military personnel from the lowest levels have to be educated and prepared but the new approaches and skills must be acquired from the seniors.

We have to emphasize that the following is stated in the Plan of Implementation of Resolution 1325 in the Ministry of Defense on preparation and standards of conduct: To develop materials (manuals, lectures, promotional materials, standards of conduct / ethics, etc.) for the implementation of Resolution 1325 in order to integrate the Policy of equality at all levels of the Armed Forces.

In this regard, the education in gender issues in the Bulgarian military academies started in 2015. The aim is to support the increased awareness on gender perspective in military operations for the future officers and to assist NATO Allies and Partners to build their gender capacity and capabilities. Topics related to issues of gender equality, gender practices, the main international documents of the UN and NATO were offered on the website of NATO Strategic Command-SACT [4].

Special attention is paid at the National Military University to leadership training that takes place in regular academic hours 
on a modular basis, with theoretical and practical exercises throughout the whole course of education. On this occasion, as a result of an active dialogue between Ministry of Defense and the representatives of BUAFWA and recommendations of NATO, steps were taken to major changes in the curricula, in modules of the Leadership Training Course. The following topics have been included in the Leadership training module which has 4 parts:

$>$ "The essence of Gender Equality Policies. International framework and documents. "- lecture; workshop and exercise;

$>$ "National framework and policies of the implementation of gender equality" lecture and workshop;

$>$ "Integration of Gender Equality Policies

in the planning, implementation and evaluation of military operations and missions." - lecture and exercise.

To summarize some of the shared examples from the Bulgarian experience and according to the 2015 Research Questionnaire UNSCR 1325, the main areas of employment where women serve are as follows (the number of women that serve in each applicable area):

- Administration 2,08\%;

- Communications 5,07\%;

- Logistics 1,4\%;

- Finance $0,3 \%$;

- Infantry $0,54 \%$;

- Intelligence $0,54 \%$;

- Legal 0,004\%;

- Musicians 0,06\%;

- Public Affairs 0,06\%;

- Other 3,7\%, Common: medical, surveyor, meteorologist.

It is obvious that the measures taken by the Ministry of Defence of Bulgaria to remove the legal and organizational barriers to implement gender perspective and to create good organizational climate in the military units are yielding results. Women in uniform can live with dignity and with expectations for career development and social support. Sometimes the problems with overcoming the prejudice and stereotypes in people's minds can delay the process which requires targeted policy, systematic work and education.

To follow the active attitudes in the military and to take adequate decisions regarding gender balance in the army, sociological research on the topic of "Organizational climate in formations and structures of the Armed Forces of the Republic of Bulgaria" has been done by the MoD. [5] It is a positive tendency that in the last years the research has included questions about the attitudes towards the service of women and people from different ethnic and cultural groups in the army. The analysis of the data shows that women soldiers are perceived as being in a relatively privileged position as compared to their male colleagues, while the presence of such a privilege for men is lacking. At the same time, the study proves that there are no signs of organizational discrimination towards females in the military. These results require research attention to the factors which are underlying the differences in the perception of men and women soldiers regarding the privilege of two sexes in the military.

\section{Conclusion.}

To finalize all reflections full of good examples, working policies and expectable troubles, the opinion of the author is that the initiatives related to gender equality will contribute to the development of the modern and affluent society. The continued empowerment of women is a responsible task both for the state authorities and for the ordinary people. It is more important to believe and to do our best, with small steps to move in the right and desired direction......as The Universal Declaration of Human Rights reads: " All human beings are born free and equal in dignity and rights". 


\section{References}

[1] Action plan for implementation of United Nations Security Council Resolution 1325 at the Ministry of Defence, www.mod.bg/en/doc/gender

[2] Chang P., Alam M., Warren R., Bhatia R. , Turkington R. , Woman leading peace, Georgetown Institute for Women, Peace and Security, 2015

[3] Norville V., The Role of Women in Global Security. Special report, United States Institute of Peace, www.usip.org

[4] Package of training and education tools - SACT, NATO, www.act.nato.int/gendertraining

[5] Report about the results of a sociological survey: "Organizational climate in formations and structures of the Armed forces of the Republic of Bulgaria", MoD - Defense Advanced Research Institute, Sofia, 2015

[6] Summary of the National Reports of NATO member and partner nations to the NATO Committee on Gender Perspectives (NCGP), 2015, www.nato.int/nato_static_fl2014/assets/pdf/pdf_2017_01/20170113_2015_NCGP_Natio nal_Reports_Summary.pdf 